\title{
LEX AETERNAM E LEX TEMPORALEM: DO DIREITO FUNDAMENTAL À EDUCAÇÃO INCLUSIVE
}

\section{ARTIGO ORIGINAL}

PRAZERES, Paulo Joviniano Alvares dos ${ }^{1}$

PAJEU, Juliana Karla ${ }^{2}$

1 Doutorando em Direito pela Universidade Católica de Pernambuco UNICAP; Doutorando em Ciências da Educação pela Universidad Autonoma de Asuncion UAA; Doutorando em Direito e Ciências Sociais pela Universidad Nacional de Cordoba UNC; Mestre em Direito pela Faculdade Damas da Instrução Crista FADIC; Mestre em Ciências da Educação pela Universidad Del Sol UNADES; Mestre em Direito das Relações Internacionais pela Universidad de la Empresa UDE; Especialista em Direito Internacional pela Faculdade Católica Paulista FACAP; Especialista em Filosofia e Sociologia pela Faculdade Venda Nova do Imigrante FAVENI; Especialista em Direito Tributário pela Faculdade INESP; Especialista em Direito Público pela Faculdade Mauricio de Nassau FMN; Graduado no curso de magistratura e demais carreiras jurídicas pela Escola de Magistratura de Pernambuco ESMAPE; Bacharel em Ciências Contábeis pelo Centro Universitário Cidade Verde UNIFCV; Bacharel em Relações Internacionais pelo Centro Universitário Internacional UNINTER; Licenciado em Pedagogia pela Faculdade FACESE; Licenciado em Filosofia pela Faculdade Entre Rios do Piauí FAERPI; Graduado em Teologia pela Faculdade de Teologia Integrada FATIN; Graduado em Direito pela Universidade Católica de Pernambuco UNICAP; Pesquisador do grupo de estudos em Educação e Direitos Humanos da Universidade Federal da Paraíba UFPB; Membro Associado e Avaliador do Conselho Nacional de Pesquisa e Pós-Graduação em Direito - CONPEDI; Presidente da Academia de Letras Jurídicas de Olinda; Advogado, Consultor Jurídico, Professor Universitário e de pósgraduações e cursos preparatórios, Presidente da Subsecção da OAB Olinda-PE.

2 Possui especialização em Direito Público pela Faculdade Inesp; especialista em Estudos de perícia forense, Criminologia e Medicina Legal pela Faculdade Inesp; MBA 
PEREIRA, Francisco Caetano ${ }^{3}$

PRAZERES, Paulo Joviniano Alvares dos. PAJEU, Juliana Karla. PEREIRA, Francisco Caetano. Lex Aeternam e Lex Temporalem: do direito fundamental à educação inclusiva. Revista Científica Multidisciplinar Núcleo do Conhecimento. Ano 04, Ed. 12, Vol. 02, pp. 52-66. Dezembro de 2019. ISSN: 2448-0959, Link de acesso: https://www.nucleodoconhecimento.com.br/lei/lex-aeternam

\section{RESUMO}

O Direito é norma que regula a vida social e coletiva, e ao mesmo tempo assegura garantias aos indivíduos que estejam sob a égide de um Estado ou nação a qual este Direito seja norma reguladora. Assim, desde as normas divinas, reguladoras da vida sob a vontade divina, leis antecedentes e naturais, assim como as legais positivas, temos a vontade de Deus, a vontade dos homens e a estrutura do Estado coexistindo harmonicamente, regulando e assegurando Direitos, dentre os quais, neste trabalho enfocamos a Educação, que é um direito universal e deve ser estendido a todas as pessoas, sendo enfocado especificamente nesta pesquisa o acesso e garantia a educação as pessoas com deficiência.

em gestão jurídica do poder judiciário; especialista em Gestão e Docência no ensino Superior pela Faculdade Novo Horizonte; Graduada em Bacharelado em Teologia pela Faculdade de Teologia Integrada-FATIN; Graduada em Direito pela Faculdade de Ciências Humanas de Pernambuco; Graduada em Bacharelado em Relações Internacionais pelo Centro Universitário Internacional- UNINTER; Graduada Bacharela em Ciências Contábeis pela Faculdade Joaquim Nabuco FJN; Presidente do Instituto Pan Americano de Ciências, Educação e Cultura.

${ }^{3}$ Doutorado em Em Direito. Especialização em Línguistica. Graduação em Bacharel Em Direito. Graduação em Licenciatura Em Letras. Graduação em Teologia. Graduação em Teologia. Graduação em Teologia. 
Palavras-chaves: Direito divino, Direito natural, Direito Positivo, Direito a Educação, deficiência.

\section{INTRODUÇÃO}

A história da pessoa humana em sociedade tem sido marcada por lutas e transformações ao longo dos séculos, fruto de suas aspirações e sonhos mais profundos, enquanto alguém que vive em busca de realização no mundo no qual está inserida.

Dessa feita, é próprio da pessoa humana a inquietação e a busca constante de superação no propósito de se adaptar a um habitat que lhe permita a concretização dos seus ideais, projetos e sonhos, tendo em vista a consecução do seu bem-estar.

Por outro lado, observa-se que, nem sempre, esses ideais, projetos e sonhos se aliam a uma expressiva e reconhecida porção da espécie humana, ponto no qual se situa a divergência desembocando em conflitos e insatisfações advindas desse desencontro.

Daí surgem grupos que se formam a partir da convergência de objetivos e, através da aproximação do conteúdo da sua luta; criam afinidades e se reforçam partindo para a conquista de espaços e possibilidades, de condições e garantias para a concretização dos ideais e sonhos, tendo em vista a realização e o bem-estar próprio, e, como consequência, estendendo-se aos seus semelhantes.

Nessa avalanche de lutas, os pontos comuns são unidos e estabelecem padrões a serem seguidos, o que com o desenrolar do tempo, consolida-se e transforma-se em algo que precisa ser cunhado, declarado e seguido. Elege-se um líder para garantir o cumprimento dos acordos e, em consenso, até com poder para punir os que transgredirem o acordo.

Fazendo um recorte na história da pessoa humana em sociedade buscando reconhecimento do seu espaço, no século XVIII a burguesia, sentindo-se lesada em seus direitos, lutou em busca da igualdade de condições pautada pelos ideais humanistas. Discorre, de forma contundente, Libâneo: 
As ideias liberais foram difundidas quando, no final do século XVIII, a burguesia lutava para arrancar o poder da nobreza feudal e do clero. Para tanto, lançou mão de ideais humanistas, ou seja, a liberdade, a igualdade, a fraternidade. No decorrer dessa luta pelo poder político e econômico, a ideia de poder baseada na posição social hereditária caí por terra, pois agora cada cidadão tem o direito de adquirir prestígio e enriquecer por mérito próprio. Assume-se, então, uma visão de homem e de mundo assentada sobre o indivíduo e sobre seus direitos naturais. Para se consolidar no poder, a burguesia inicialmente reivindica tais direitos não somente para si, mas também para todos os que sofriam a opressão da nobreza e do clero, inclusive, portanto, as camadas populares (LIBÂNEO, 2005, p. 62-63).

O impulso para o reconhecimento dos direitos individuais e a valorização da pessoa humana e da liberdade do cidadão tem a sua raiz na Declaração dos Direitos Humanos de 1789. E, em decorrência, a conferência mundial da ONU, realizada em 1948, com representantes de todas as nações do mundo, promulga a Declaração Universal dos Direitos Humanos, como ideal comum a ser vivenciado por todas as nações e povos. Direitos humanos tidos como fundamentais no reconhecimento da dignidade da pessoa humana, os quais passam com isto a gozar de destaca relevância na hierarquia do ordenamento jurídico.

Assiste-se, a partir de então, ao reconhecimento da pessoa enquanto ser humano dotado de vida e com direitos inatos, inalienáveis, intransferíveis, potencial este que deve ser respeitado e sustentado através de leis que the possibilitem seu desenvolvimento saudável e seguro. Em decorrência o mundo, entendido aqui como sociedade, deve ser estruturado dentro de princípios que assegurem a sua concretização.

Ainda, a dimensão história faz compreender a luta pelos direitos desde o século XVIII com a Revolução Francesa que trouxe como herança, vários direitos; os de primeira geração, como direito à vida, à liberdade, à expressão livre. E, em sequência, os de segunda geração, dentre eles, a educação e, posteriormente, de terceira, fala-se até em direitos de quarta geração.

O direito à Educação é considerado como um caminho favorável de superação dos meios de opressão porque proporciona o desenvolvimento das potencialidades 
humanas e oportuniza o acesso ao conhecimento, elemento responsável pelo crescimento humano e pela transformação social.

A efetivação do direito à educação ficou determinado legalmente que seria da responsabilidade do Estado, sendo assegurado através de políticas públicas. Compreendendo que, decorrente desse direito, ampliar-se-ia a liberdade, pois a liberdade natural passa a ser concretizada pela possibilidade de aquisição de bens e a sua administração, "instaura-se, assim, um novo sistema de relações sociais onde a liberdade individual se associa com o direito de propriedade" (LIBÂNEO, 2005, p.63).

No bojo de todas essas questões está que "o princípio da dignidade humana é considerado a base de todo o ordenamento jurídico brasileiro, além de que norteia a questão dos direitos fundamentais" (SOUSA, 2010, p.33). Razão pela qual não se pode negar ou camuflar esse direito para o cidadão tendo em vista interesses alheios aos da educação.

Da sua parte a Igreja Católica sempre reforçou sua posição em defesa do ser humano em qualquer que seja a situação em que se encontre. Expressando-se com todo o vigor e sabedoria em seus documentos:

Por isso, o Concílio, testemunhando e expondo a fé do Povo de Deus por Cristo congregado, não pode manifestar mais eloquentemente a sua solidariedade, respeito e amor para com a inteira família humana, na qual está inserido, do que estabelecendo com ela diálogo sobre esses vários problemas, aportando a luz do Evangelho e pondo à disposição do gênero humano as energias salvadoras que a Igreja, conduzida pelo Espírito Santo, recebe do seu Fundador. Trata-se, com efeito, de salvar a pessoa do homem e de restaurar a sociedade humana. Por isso, o homem será o fulcro de toda a nossa exposição: o homem na sua unidade e integridade: corpo e alma, coração e consciência, inteligência e vontade (ENCÍCLICA GAUDIUM SPES, 1965, p 1).

Por conseguinte, o presente artigo discorre sobre questões relativas ao direito à educação formal e sistematizada para a pessoa com deficiência, em específico, com Transtorno de Espectro Autista. 


\section{NOS TERMOS DA LEI NATURAL E POSITIVA}

O Criador dotou o ser humano de uma dignidade suprema e inviolável. É de inteira grandeza destacar o acento que a Sagrada Escritura dá à pessoa humana ressaltando a sua semelhança com o Criador, conforme encontramos na Encíclica Papal:

A Sagrada Escritura ensina que o homem foi criado «à imagem de Deus», capaz de conhecer e amar o seu Criador, e por este constituído senhor de todas as criaturas terrenas, para as dominar e delas se servir, dando glória a Deus. «Que é, pois, o homem, para que dele te lembres? Ou o filho do homem, para que te preocupes com ele? Fizeste dele pouco menos que um anjo, coroando-o de glória e de esplendor. Estabeleceste-o sobre a obra de tuas mãos, tudo puseste sob os seus pés» (Salmo 8, 5-7) (ENCÍCLICA GAUDIUM SPES, 1965, p 7).

A história nos narra que a partir do século XVIII com o surgimento dos direitos humanos de primeira geração e das subsequentes as decisões políticas e sociais tomam o rumo do respeito aos valores da pessoa e da sua dignidade humana como o direito à vida, à liberdade, à propriedade, à saúde, ao trabalho, à educação, dentre outros. A ONU em assembleia reconheceu essa dignidade e estabeleceu em documento de direito a ser observado por todos os povos e nações promulgando a Declaração Universal dos Direitos Humanos.

Segundo o pensamento de Bobbio (2004, p.33) essa declaração "representa a consciência histórica que a humanidade tem dos próprios valores fundamentais". Dentre outras considerações pontua no texto promulgado:

Considerando que o reconhecimento da dignidade inerente a todos os membros da família humana e de seus direitos iguais e inalienáveis é o fundamento da liberdade, da justiça e da paz no mundo; considerando que os povos das Nações Unidas reafirmaram, na Carta, sua fé nos direitos humanos fundamentais, na dignidade e no valor da pessoa humana e na igualdade de direitos dos homens e das mulheres, e que decidiram promover o progresso social e melhores condições de vida em uma liberdade mais ampla (DUDH, 1948).

No Brasil, a história do texto constitucional federativo se nos apresenta o reconhecimento desses direitos valorativos da pessoa humana. A Constituição de 1988 apresenta-nos o fruto da caminhada que a nação fez com relação à conquista 
dos seus direitos, registrando o resultado dessa luta ao imprimir em seu texto, logo no Artigo primeiro, a dignidade humana como fundamento da convivência social. Prossegue estabelecendo como um dos seus objetivos fundamentais, no Artigo 3o, inciso IV: "promover o bem de todos, sem preconceitos de origem, raça, sexo, cor, idade e quaisquer outras formas de discriminação" (CONSTITUIÇÃO FEDERAL, 1988, p. 11).

No que tange à educação a Constituição Federal assume a visão democrática e estabelece como dever do Estado a sua oferta nomeadamente aos alunos que são deficientes; até abre espaço e possibilidade para o atendimento no turno noturno.

A Constituição brasileira incorporou bem a visão democrática do direito à educação, nesse aspecto (art. 208, III, VI), estabelecendo que o dever do Estado com a educação será efetivado mediante a garantia do atendimento especializado aos portadores de deficiência preferencialmente na rede regular de ensino, e mesmo na oferta de ensino noturno regular, o que é, sem dúvida, dirigido à classe trabalhadora (MEDEIROS, 2001, p. 8)

Percebe-se, todavia, no texto constitucional a clara e consistente fundamentação do compromisso, no sentido do que the diz respeito, que se tem com a dignidade da pessoa humana e o favorecimento das possibilidades ao exercício da cidadania garantindo legalmente condições adequadas, próprias e necessárias ao desenvolvimento da vida em todos os aspectos.

Uma vez reconhecida a dignidade do ser humano enquanto alguém digno de direitos a serem velados pelo Estado Democrático de Direito, em continuidade aos Direitos Fundamentais de $2^{2}$ geração tendo por princípio a igualdade, a sociedade foi mobilizada a declarar e definir seus interesses no tocante à participação na vida social visando o crescimento da sociedade. Assim

O direito à igualdade fez com que todos fossem considerados formalmente iguais perante a lei. Por sua vez, a lei foi tida como o legítimo instrumento de uma sociedade unida por um contrato social, sua legitimidade estaria configurada porque todos deram 0 seu consentimento, pelo contrato social, para que ela operasse efeitos. Neste panorama, a lei afirmaria no plano ideal a igualdade de todos, já que todos integrariam o contrato social (BRANDÃO, 2014, p 11). 
Com essa consciência de igualdade cabe ao Estado aparelhar as instituições para desenvolverem um ensino de qualidade para todos, mesmo que os inúmeros obstáculos dificultem a crença na possibilidade de instaurar um processo em que o conhecimento científico esteja ao alcance também das pessoas com deficiência. Defende essa posição Sousa:

Portanto, dar aos indivíduos um ensino de qualidade é papel da escola, assegurado constitucionalmente, como um dos pressupostos do direito à educação e ao desenvolvimento social. Educar cientificamente é preparar para o futuro, é formar cidadãos participantes e com consciência crítica. Todavia, não são poucos os obstáculos para a implementação de políticas públicas voltadas para a democratização do conhecimento científico. Só para citar alguns, têm-se: deficiências na formação de professores; escassez de recursos; fragmentação de políticas públicas que contemplem a complexidade do sistema educacional brasileiro e que permitam uma interferência efetiva na realidade (SOUSA, 2010, p. 71).

Vislumbrando, por conseguinte, esse horizonte de acesso à educação como um direito fundamental de todos, Sousa pontua como modelo imprescindível: "A definição de políticas públicas para a educação no Brasil parte de um modelo de interação entre diversos sistemas: político, econômico, jurídico, entre outros" (SOUSA, 2010, p. 84).

\section{EM BUSCA DA PRÁTICA DA IGUALDADE NO CAMPO EDUCACIONAL}

A educação como direito fundamental de segunda geração tem sido desenvolvida dentro de parâmetros que ainda não conseguiu contemplar todas as crianças ou adolescentes atendendo as suas necessidades educacionais especiais. Sousa apresenta a questão da falta de estruturação na perspectiva da inclusão para o atendimento a essas pessoas. Por isto, a necessidade de criar leis que venham a inibir práticas discriminatórias e marginalizadoras de um expressivo número de famílias que são lesadas em seus direitos.

Muito embora a educação, como pontua Medeiros (2001, p. 29), tenha recebido: "O tratamento do direito de acesso como direito subjetivo público significou, por outro 
lado, que a educação fundamental foi elevada à categoria de serviço público essencial, devendo o poder público fornecê-lo a todos".

O Decreto no 6.949/2009 promulga a Convenção Internacional sobre os Direitos das Pessoas com Deficiência e seu Protocolo Facultativo, assinados em Nova York, em 30 de março de 2007, a qual traz a terminologia e a caracterização da pessoa com deficiência legalmente reconhecida em seus direitos:

Pessoas com deficiência são aquelas que têm impedimentos de longo prazo de natureza física, mental, intelectual ou sensorial, os quais, em interação com diversas barreiras, podem obstruir sua participação plena e efetiva na sociedade em igualdades de condições com as demais pessoas. (DECRETO oㅜ 6.949/2009, Art 1ํ).

O referido decreto em seu Preâmbulo ressalta o sentido e a importância do documento, enquanto defensor dos direitos das pessoas com deficiência, dentre outras matérias para conscientização da sociedade:

- Reconhecendo também que a discriminação contra qualquer pessoa, por motivo de deficiência, configura violação da dignidade e do valor inerentes ao ser humano,

- Reconhecendo a necessidade de promover e proteger os direitos humanos de todas as pessoas com deficiência, inclusive daquelas que requerem maior apoio,

- Reconhecendo a importância da acessibilidade aos meios físico, social, econômico e cultural, à saúde, à educação e à informação e comunicação, para possibilitar às pessoas com deficiência o pleno gozo de todos os direitos humanos e liberdades fundamentais (DECRETO $\mathrm{n}^{\circ}$ 6.949/2009).

De forma que a pessoa com deficiência tem total amparo legal e, por isto, é reconhecida na sua igualdade de condições e direitos, assim como, tem o necessário benefício e amparo legal frente às situações que venham a infringir seus direitos: "Os Estados Partes reconhecem que todas as pessoas são iguais perante e sob a lei e que fazem jus, sem qualquer discriminação, a igual proteção e igual benefício da lei (DECRETO no 6.949/2009, Art 5º, inciso 1). Portanto, alicerçada no amparo legal a pessoa deficiente ou a sua família deve buscar a assistência a qual tem direito. 
Coube ao direito fundamental à educação lançar luzes na vida da criança - futuro adulto - por assegurar a educação e de qualidade para todos. Podendo, a partir dessa garantia, desenvolver as competências e habilidades que lhe darão condições de exercer a cidadania, continuar seus estudos e inserir-se no mundo do trabalho, conforme o estabelecido na Lei da Educação Nacional - LDB no 9394/96:

Aprimorar o educando como pessoa humana; possibilitar o prosseguimento de estudos; garantir a preparação básica para o trabalho e a cidadania; dotar o educando dos instrumentos que o permitam "continuar aprendendo", tendo em vista o desenvolvimento da compreensão dos fundamentos científicos e tecnológicos dos processos produtivos (LDB no 9394/96, Art.35, incisos I a IV).

Considerando-se que a possibilidade que se tem de realizar um estudo que venha a oferecer um reconhecido cabedal de conhecimentos e subsídios adequados para a formação de cidadãos competentes e comprometidos com a transformação social advém da educação, conforme Sousa:

De maneira mais ampla, o acesso à educação propicia 0 desenvolvimento de uma sociedade livre, mais justa e solidária. É o retorno que o indivíduo "educado" formalmente dá para a sociedade, pois passa a ter consciência de sua individualidade, atrelado a forte sentimento de solidariedade social (SOUSA, 2010, p.30).

Acredita-se que assumir a educação como reconhecimento da dignidade humana e prática da liberdade com estratégias educacionais eficazes consolida a formação da pessoa humana, prepara-a para o exercício da cidadania, produz a libertação da consciência e the oferece os elementos próprios para a superação das suas limitações. Sendo possível, pois, através da sua vivência exercer o seu ser históricosocial. Nesta dimensão, enfatiza Freire:

E é como seres transformadores e criadores que os homens, em suas permanentes relações com a realidade, produzem, não somente os bens materiais, as coisas sensíveis, os objetos, mas também as instituições sociais, suas ideias, suas concepções. Através de sua permanente ação transformadora da realidade objetiva, os homens, simultaneamente, criam a história e se fazem seres históricos-sociais (FREIRE, 2005, p.106). 
Todo esse contexto atual de sociedade democrática instiga a que se busque novas formas de atuação e impulso para que se conheça as bases legais que respaldam os direitos dos cidadãos, para que possam definir o seu lugar na sociedade e fundar os pilares para a sua prática assistindo a contento as pessoas que solicitam o serviço educacional.

Nesse cenário de discussões é considerado como relevante o respeito à dignidade humana da pessoa com deficiência e o devido reconhecimento do seu direito à educação como direito fundamental. No entanto, registra-se lamentavelmente que no Brasil esse direito tem sido ignorado pelas autoridades estatais, expõe Sousa indo mais além: "E isso fica mais latente quando se constata que a Carta de 1988 elevou o direito à educação ao status de direito público subjetivo. Nesse contexto, o sentido de realização desse direito é forte a ponto de afastar qualquer recusa do Estado em efetivá-Io" (SOUSA, 2010, p 30).

Afirma-se, mais uma vez, a educação como direito fundamental a ser garantido pelo Estado à pessoa em idade de escolaridade, condição determinante para o pleno desenvolvimento do ser humano e consequente acesso aos demais direitos. Decorrente desse direito vários outros se confirmarão em caráter de sobrevivência humana, como relata Imbernón:

Sem o cumprimento satisfatório do direito à educação, não só a vida de cada um empobrece e limita seu horizonte, mas também, dificilmente, podem ser realizados outros direitos, como a livre expressão, a participação política ou o direito ao trabalho nas sociedades avançadas (IMBERNÓN, 2000, p. 46).

A conotação da universalização dos direitos fundamentais traduz o que Imbernón nos apresenta: "significa ter que dispor de instituições em quantidade suficiente e de qualidade aceitável para viabilizar o exercício de tal direito em condições de igualdade" (IMBERNÓN, 2000, p. 53). Isto remete a indagações sobre a realidade educacional brasileira em seus vários aspectos indo da legislação à prática.

Assiste-se às dificuldades e entraves que geram desconforto nos que buscam a cumprimento desse direito ou dele dependem. $O$ descumprimento gera um conjunto 
de situações que afetam a realização pessoal, põem em crise o sistema educacional como um todo e o desenvolvimento do país:

A crise da educação acumula hoje as denúncias de diagnósticos velhos e novos. Afeta as políticas educativas, as instituições escolares, a formação de professores, os currículos, os sistemas de gestão, a estruturação das escolas com as famílias, os métodos educativos, etc. Pondo em questão tanta coisa ao mesmo tempo, é natural que o diagnóstico pareça cada vez mais grave e a situação, menos auspiciosa. (IMBERNÓN, 2000, p. 57)

Por outro lado, a população em sendo educada dentro da esteira garantida por lei terá condições de gerir competentemente as demandas econômicas e sociais. Contará, enfim, com um povo competentemente preparado para a transformação social e a satisfação dos que têm diagnóstico de deficiência por serem tratados com dignidade dentro do valor inerente da pessoa humana.

\section{O DESAFIO DE EDUCAR PESSOAS COM DEFICIÊNCIA}

A nossa trajetória é baseada nas ações e escolhas de nossos antepassados, mais precisamente, em razão de nossa tradição, os gregos, que são base de nossa hodierna cultura. $O$ destaque da tradição grega remete que a mesma seria um privilégio da casta de guerreiros. (MARROU, 1969, p. 20).

Em Homero, o reconhecimento do povo grego obteve em sua mais ampla plenitude a figura do educador, o que fez com que os seus textos fosse a base que formara a cultura do povo grego. Na realidade, "o conteúdo técnico da educação grega evoluiu profundamente, refletindo as transformações profundas de toda a civilização: somente a ética de Homero podia conservar, ao lado de seu valor estético, imperecível, uma projeção permanente" (MARROU, 1969, p. 27).

De outra forma, a evolução histórica nos permitiu que atualmente, ladrilhado com o amparo legal que assegura ao indivíduo a proteção por parte do Estado os Direitos e avanços da pessoas, de seus direitos, precisamente em respeito as conquistas sócias em razão das lutas travadas pelo reconhecimento da necessidade que permita aos indivíduos a plenitude de garantias que assegurem o desenvolvimento de forma plena. 
Continuando, a Carta Magna brasileira apresenta o direito à educação como um direito de personalidade fundamental imprescindível à vida com dignidade. No Capítulo III trata da educação, artigos 205 a 214, onde o constituinte elenca objetivos e diretrizes sobre os quais o sistema educacional do país deve se pautar. Nomeia crianças e adolescentes como titulares do direito à educação fazendo menção à família, à sociedade e ao Estado como responsáveis por sua garantia e proteção. Faz clara menção aos deficientes que devem receber atendimento para fins educacionais especializado.

Realça-se, por ora, a 13.146/2015, incorporada em nosso sistema legal após a adesão a convenção de Nova York que objetivara a promoção de parâmetros de igualdade, o gozo pleno de direitos e liberdades por parte das pessoas com deficiência, com objetivo de inclusão social e cidadã.

Referido dispositivo normativo disciplina acerca da educação, apontando qual a forma de se disponibilizar meios para alcance do desenvolvimento do potencial da pessoa no campo educacional, direito o qual haverá de se garantir inobstante a condição da deficiência apresentada pelo indivíduo.

A educação constitui direito da pessoa com deficiência, assegurado sistema educacional inclusivo em todos os níveis e aprendizado ao longo de toda a vida, de forma a alcançar o máximo desenvolvimento possível de seus talentos e habilidades físicas, sensoriais, intelectuais e sociais, segundo suas características, interesses e necessidades de aprendizagem. (LEI № 13.146/2015, Art. 27).

Posicionamento à luz da Declaração Universal dos Direitos Humanos - DUDH, promulgada em 1948, que circunscreve: "Toda pessoa tem direito à instrução. A instrução será gratuita, pelo menos nos graus elementares e fundamentais. A instrução elementar será obrigatória. A instrução técnico-profissional será acessível a todos, bem como instrução superior, está baseada no mérito" (DUDH, Artigo 26, inciso 1).

Em continuidade, a referida declaração assim regulamenta: 
2. A instrução será orientada no sentido do pleno desenvolvimento da personalidade humana e do fortalecimento do respeito pelos direitos humanos e pelas liberdades fundamentais. A instrução promoverá a compreensão, a tolerância e a amizade entre todas as nações e grupos raciais ou religiosos, e coadjuvará as atividades das Nações Unidas em prol da manutenção da paz.

3. Os pais têm prioridade de direito na escolha do gênero de instrução que será ministrada a seus filhos. (DUDH, Artigo 26, inciso 2 e 3 ).

No Brasil, o Decreto 6.949/2009, em seu Artigo 24 regimenta o tratamento de natureza igual e equitativa o qual se assegura a pessoa com deficiência garantindo-Ihes inclusão no sistema educacional, sem discriminação e capaz de fazer evoluir suas potencialidades. Traçando os seguintes objetivos:

a) O pleno desenvolvimento do potencial humano e do senso de dignidade e autoestima, além do fortalecimento do respeito pelos direitos humanos, pelas liberdades fundamentais e pela diversidade humana;

b) O máximo desenvolvimento possível da personalidade e dos talentos e da criatividade das pessoas com deficiência, assim como de suas habilidades físicas e intelectuais;

c) A participação efetiva das pessoas com deficiência em uma sociedade livre. (Decreto $n^{\circ}$ 6.949/2009, Art. 24, § 1ํ)

Determinação que traz em sua substância além do reconhecimento a exigência de acoes em prol da concretização legal frente a tantas pessoas as quais são desvalidas do benefício em razão de uma realidade derradeira de lutas improdutivas. Assim temos que a lei também determina que as pessoas portadoras de deficiência tenham acesso ao sistema educacional de forma gratuita, de maneira igualitária em condições e não Ihes faltem condições que facilitem a aprendizagem.

O respaldo de ordem legal é robusto e convincente na instauração do direito e da sua garantia. No entanto, os desafios possuem dimensões imensas, o que estabelece a imperiosa necessidade de crer na superação de tal crise e assim observar de forma 
mais adiantada: "Será desafio do futuro conseguir que o lugar criado na vida de todos os sujeitos pela educação institucionalizada seja preenchido com fins com sentido próprio" (IMBERNÓN, 2000, p.59).

Reconhece-se, no entanto, que "o problema fundamental em relação aos direitos do homem, hoje, não é tanto o de justificá-los, mas o de protegê-los. Trata-se de um problema não filosófico, mas político" (Bobbio, 2004, p. 23). Esta constatação de Bobbio nos situa no tempo e no espaço quando ao nos depararmos com situações inusitadas de descumprimento das diretrizes normativas.

Vê-se, então, a necessidade de aceitação das diferenças e urgência em aplicar a inclusão, o que possibilitará enxergar o outro a partir das suas habilidades e de seu potencial de desenvolvimento, e não, simplesmente, de suas limitações e de estereótipos ditados pela sociedade. Postura que vai muito além da mera tolerância porque se expressa no acolhimento e no favorecimento de um conjunto de condições a propiciar o desenvolvimento ou surgimento de novas habilidades e suas competências que venha a possibilitar a sobrevivência segura e tranquila da pessoa portadora de deficiência, aliada ao bem-estar social que daí emerge.

Por conseguinte, a fundamentação exposta elenca uma série de questões inacabadas e pertinentes relativas à educação brasileira e ao ordenamento jurídico, requisitando um debruçar atento e determinado para conhecer mais amplamente a matéria e analisá-la, tendo em vista o real cumprimento dos dispositivos legais para, enfim, assegurar esse direito fundamental tendo como meta a construção de uma sociedade justa, igualitária e solidária possível a todos os cidadãos, enfim, uma sociedade sustentável.

\section{CONSIDERAÇÕES FINAIS}

É imprescindível que em uma sociedade dentre as preocupações com a produção, com os serviços prestados e a satisfação das necessidades pessoais, não se perca de vista a pessoa em sua inteireza e se enxergue as suas carências primordiais a fim de buscar condições que garantam e respeitem o ser humano na sua dignidade. 
Daí a importância de investimento em projetos que viabilizem a concretização e aplicação dos dispositivos legais. Assim, é basilar o tratamento relacional centrado nas potencialidades, qualidades e valores da pessoa, como também, nos fatores intrínsecos e valores intangíveis característicos da pessoa, ainda que lide com alguma deficiência.

Conhecer a pessoa deficiente, suas potencialidades, suas capacidades, sua história, suas necessidades, seus sonhos, projetos e desejos são elementos que direcionam e lançam luzes para delinear as estratégias de atuação através da sábia coordenação do profissional especializado que dará sentido e significado relevantes para a vida da pessoa com necessidades educacionais especiais e mobilizará os órgãos públicos e as instituições educacionais para a efetivação das políticas públicas.

O clima de apoio e de valorização humana, de trabalho de cunho educativo, de aquisição, ampliação e aprofundamento constante do conhecimento, solicita do profissional que lida com pessoas com deficiência a atitude permanente de pesquisador, de alguém que mergulha no universo acadêmico a fim de buscar sustentação teórica para a sua prática e de projetar ações que atendam às realidades dos sujeitos de direito.

Finalmente, de tudo o que foi discorrido, que se considere prioritariamente o bemestar da pessoa com necessidades especiais e seu crescimento pessoal e intelectual no favorecimento de aprendizagens significativas que assegurem 0 seu desenvolvimento integral, capacitando-o para ocupar seu espaço na sociedade contribuindo de forma competente e eficaz com a transformação social.

\section{REFERÊNCIAS}

BOBBIO, Noberto. A era dos direitos; tradução Carlos Nelson Coutinho; apresentação de Celso Lafer. - Nova ed. — Rio de Janeiro: Elsevier, 2004. — $8^{\text {a }}$ reimpressão. 
BOSA, Cleonice; CALLIAS, Maria. Autismo: breve revisão de diferentes abordagens. Psicol. Reflex. Crit. [online]. 2000, vol.13, n.1, pp.167-177. ISSN 01027972. http://dx.doi.org/10.1590/S0102-79722000000100017.

BRANDÃO, Cláudio. In: BRANDÃO, Cláudio (Coordenador). Direitos Humanos e Fundamentais em Perspectiva. São Paulo: Atlas, 2014.

BRASIL. Constituição da República Federativa do Brasil. Brasília: Senado Federal, 1988.

. Lei n. 9.394, de 20 de dezembro de 1996, Lei de Diretrizes e Bases as Educação.

- Política Nacional de Educação Especial. Série Livro. Brasília, DF: MEC/SEESP, 1994.

CARNEIRO, Moaci Alves. Direito Fundamental à Educação. In: BRANDÃO, Cláudio (Coordenador). Direitos Humanos e Fundamentais em Perspectiva. São Paulo: Atlas, 2014.

CRUZ, Talita. Autismo e Inclusão: experiências no ensino regular. Jundiaí, Paco Editorial: 2014.

DECLARAÇÃo DE SALAMANCA: Sobre Princípios, Políticas e Práticas na Área das Necessidades Educativas Especiais, 1994, Salamanca - Espanha.

FREIRE, Paulo. Pedagogia do Oprimido. Rio de Janeiro, Paz e Terra, 2005.

IMBERNÓN, Francisco. Formação permanente do professorado: novas tendências. tradução de Sandra Trabucco Valenzuela. São Paulo: Cortez, 2000.

JÚNIOR, José Ferreira Belisário; CUNHA Patrícia. A Educação Especial na Perspectiva da Inclusão Escolar: Transtornos Globais do Desenvolvimento Brasília: Ministério da Educação, Secretaria de Educação Especial; Fortaleza: 
Universidade Federal do Ceará, 2010. v. 9. (Coleção A Educação Especial na Perspectiva da Inclusão Escolar).

LEI № 15.487, DE 27 DE ABRIL DE 2015. Dispõe sobre a proteção e os direitos da pessoa com Transtorno de Espectro Autista no Estado de Pernambuco e dá outras providências.

LIBÂNEO, José Carlos. Democratização da Escola Pública - a pedagogia críticosocial dos conteúdos. Edições Loyola.2005.

MARROU, Henri Irénée. História da Educação na Antiguidade. Tradução: Mário Leônidas Casanova São Paulo: Editora Herder. 1969.

MEDEIROS, Mônica Jacqueline Sifuentes Pacheco de. 0 acesso ao ensino fundamental no Brasil: um direito ao desenvolvimento. Rio de Janeiro: América Jurídica, 2001.

ONU. Declaração Mundial sobre Educação para todos - Jomtien - 1990. Disponível em: <http:// www. direitoshumanos.usp.br/index.php/Declara\%C3\%A7\%C3\%A3o-Universal-dosDireitos-Humanos/declaracaouniversal-dos-direitos-humanos.htm>. Acesso em 24 de julho de 2019.

PAPA PAULO VI. Carta Encíclica GAUDIUM ET SPES. São Paulo: Paulinas. 1965.

SILVA, Aida Maria Monteiro; COSTA, Valdelúcia Alves da. (orgs.). Educação Inclusiva e Direitos Humanos: perspectivas contemporâneas. 1 ed. São Paulo, Cortez, 2015. - (Coleção Educação em Direitos Humanos).

SOUSA, Eliane Ferreira de. DIREITO À EDUCAÇÃO: requisito para o desenvolvimento do País. São Paulo. Saraiva, 2010 - (Série IDP).

Enviado: Dezembro, 2018.

Aprovado: Dezembro, 2019. 